\title{
Educación y diversidad: Interpretación de El Huésped, de Guadalupe Nettel
}

\author{
(Education and diversity: Interpretation of El huésped, by Guadalupe \\ Nettel)
}

\section{Elizabeth HernáNDEZ AlvíDrez (D), Universidad Pedagógica Nacional-Ajusco, Ciudad de México, México}

\author{
Volumen 4, Número 1
}

Enero-Junio de 2019

p. $26-46$

Este número se publicó el 30 de junio de 2019

Artículo recibido: 4 de septiembre de 2018

Artículo aceptado: 23 de marzo de 2019

ISSN: 2448-5942, doi: https:// doi.org/10.36799/el.v4i1.57

\section{Citar este artículo como:}

Hernández Alvídrez, E. (2019). Educación y diversidad: Interpretación de El Huésped, de Guadalupe

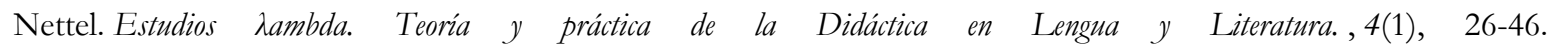
https://doi.org/10.36799/el.v4i1.57

Derechos de autor: El autor o autores conservan en todo momento sus derechos morales y patrimoniales sobre la obra; la obra no se puede alterar, transformar o ampliar; siempre debe reconocerse la autoría del documento referido. Ninguna de las modalidades de los documentos publicados en Estudios Aambda. Teoría y práctica de la didáctica en lengua y literatura tienen fines comerciales de naturaleza alguna.

Los contenidos de este artículo están bajo una licencia de Creative Commons Atribución No Comercial- Sin Derivadas 4.0 Internacional. (c) (i) 


\title{
Educación y diversidad: Interpretación de E1 Huésped, de Guadalupe Nettel ${ }^{1}$
}

\author{
Education and diversity: Interpretation of El huésped, by Guadalupe Nettel
}

\section{ELIZABETH HERNÁNDEZ ALVÍDREZ ${ }^{2}$}

\author{
- ¿Cómo haces para vivir sin una pierna? \\ El Cacho sonrió. \\ -Ya no la necesito tanto. Estoy acostumbrado a ser $\boldsymbol{s}^{3}$ sin ella. Es un rasgo \\ más de mi personalidad fascinante. \\ - ¿Pero cómo pudiste resignarte? \\ - Alprincipio la seguía sintiendo, como todos los que pierden una parte del \\ cuerpo, pero después decidí creer que nunca la babía tenido y por lo tanto no \\ podia bacerme falta. \\ - Supongamos que a mi me pasa lo contrario. \\ -¿Qué quieres decir? \\ - Supongamos que sin baber perdido un ojo baya dejado de sentirlo. \\ -No creo que sea posible - afirmó. \\ -Cacho -le dije con la voz nuevamente diluida-, estoy perdiendo la vista.
}

(Nettel, 2013, 140)

\section{RESUMEN}

El presente artículo es producto de una investigación sobre la pertinencia de la hermenéutica literaria en la formación de profesionales de la educación. Esta orientación de la lectura de textos literarios se considera idónea como enfoque filosófico que se aplica a los fines de la educación. Es decir, se interesa en atender a la pregunta por el tipo de ser humano cuya formación se promueve a través de la lectura. Como productos de la indagación se elaboran estudios críticos sobre narrativa literaria como propuestas de lectura que, a través de la interpretación, apoyen la construcción de valores con la mediación cultural que propicia la narrativa literaria. El tema específico en el cual se centra la reflexión es la formación de valores de sensibilidad hacia la diversidad. En el presente trabajo se intenta una comprensión de las personas con ceguera como diversidad ontológica que tiene repercusiones en la condición sociocultural de quienes se encuentran en esta circunstancia. La obra narrativa que se interpreta desde esta perspectiva es la novela El Huésped, de la escritora mexicana Guadalupe Nettel. El análisis de la novela está centrado en la comprensión de la transformación del personaje narrador en su proceso de debilitamiento visual que la involucra en un mundo de marginación de los sujetos que viven en esta diversidad. La metodología utilizada corresponde al enfoque de la hermenéutica de Giorgio Agamben con la teoría de las signaturas, como análisis del discurso, así como a la teoría narrativa de la hermenéutica de Paul Ricoeur, en el seguimiento de la trayectoria del personaje.

PALABRAS CLAVE: Diversidad, educación, interpretación, narrativa

\begin{abstract}
This article is product of research about pertinence of literary hermeneutics in formation of education professionals. This orientation of Reading literary texts is considered suitable to be applied as a philosophical frame of educational purposes. It means to be interest for pay attention to the question for the human been that we pursue with Reading. The products

${ }^{1}$ Este trabajo forma parte de la investigación "La pertinencia educativa de la hermenéutica de Giorgio Agamben en la comprensión de la diversidad mediante la narrativa literaria” registrada en el Área de Diversidad e interculturalidad de la Universidad Pedagógica Nacional-Ajusco.

2 Elizabeth Hernandez Alvídrez. Profesora/investigadora de tiempo completo (Diversidad e interculturalidad) en la Universidad Pedagógica Nacional.ehernandezalvidrez@hotmail.com. ORCID. https://orcid.org/0000-0002-2505-2398

${ }^{3}$ Las negritas son mías, en el original aparece en cursivas.
\end{abstract}

Artículo recibido: 4 de septiembre de 2018

Artículo aceptado: 23 de marzo de 2019

Hernández doi: https://doi.org/10.36799/el.v4i1.57 Volumen 4, Número 1, Año 2019, ISSN: 2448-5942 
of research consist in critical Works about literary narrative texts in order to create Reading proposals that support the construction of values with cultural mediation of literary narrative. The specific task for reflection is the manifestation of sensibility to diversity. In the analysis work the purpose is comprehension of blindness circumstances as an ontological diversity with social and cultural affections for whose lives in this circumstance. The narrative work that is interpreted from this perspective, corresponds to the novel El buésped by Mexican writer Guadalupe Nettel. The work of analysis consists in comprehension of transformation that suffers the character Ana in her process of visual lost that involves her in a marginal world, where persons live in this diversity. The methodological process in speech analysis follows signature concept from hermeneutics of Giorgio Agamben. Also it is applied narrative concept from hermeneutics of Paul Ricoeur, in following the character path.

KEY WORDS: Diversity, education, interpretation, narrative

\section{INTRODUCCIÓN}

La justificación práctica de la investigación de la que se deriva este artículo, consiste en que en la formación de profesionales de la educación no se ha tomado en cuenta -o se ha hecho muy escasamente- la aportación de la narrativa de ficción, como otra vía de construcción de conocimientos que contribuyen a la formación humanística de quienes estudian estas profesiones. Por otra parte, el enfoque hermenéutico adoptado se justifica por favorecer las finalidades de la educación como sustento pedagógico necesario en la práctica educativa. El propósito pedagógico del enfoque hermenéutico de la lectura en la formación de profesionales de la educación que se pretende propiciar en esta investigación, consiste en formar lectores que a través de la lectura de narrativa literaria, puedan aumentar y enriquecer su competencia hacia la comprensión de la diversidad, asimismo de las circunstancias que pueden existir en las vidas de quienes se encuentran en un contexto en el que son consideradas diversas en relación con una "normalidad", establecida desde discursos socioculturales y económicos que afectan la inclusión justa en los entornos de la vida cotidiana a que se tiene derecho humanamente. Esta finalidad está ligada a una concepción de la literatura narrativa como la describe Moreno-Durán:

La novela -acaso el género literario que más se aproxima a la función de captary aprehender la realidades, antes que todo, un instrumento mediante el cual la palabra, tras superar el mero dato empírico de la evidencia exterior, basta para sugerir, suscitar y comprender toda una cosmovisión y todo un mundo que, antes, $y$ de otra forma, no nos eran posibles $(2002,17)$.

Esta manera de relacionar la ficción narrativa con la vida cotidiana, hace ver que la mirada enfocada en los hechos desde las ciencias sociales, no es suficiente para una formación humanística como la que debería propiciarse en los profesionales de la educación. Sostenemos que para ello es necesaria la imaginación a través de la literatura. Es pertinente en este aspecto 
lo que señala Terry Eagleton respecto de la relación entre la literatura de ficción y el mundo empírico, tal como se vive en una determinada circunstancia histórica:

Cuando describimos una obra como realista, no queremos decir que esté más cerca de la realidad que la literatura no realista de un modo absoluto. Lo que decimos es que se ajusta a lo que las personas de una determinada época y lugar tienden a considerar como realidad $(2017,145)$.

Esta idea de lo que se considera como realidad, concuerda con la fase de prefiguración que señala Ricoeur, por lo que una tarea del estudio de la narrativa consiste en explicitar las huellas ideológicas, tanto en un aspecto positivo como en el negativo que señala Ricoeur, cuando habla de metáforas muertas, entendidas como una comprensión anquilosada del mundo. Eagleton lo enuncia de la siguiente manera, cuando se refiere a la interpretación de las obras de la narrativa literaria:

No se trata tanto de que contengan significado, sino de que lo generen. Una vez más, esto no equivale a sugerir que todo vale [...] Un motivo para ello es que el significado es un asunto público. No puede haber un significado del que yo sea el único propietario [...] El significado pertenece al lenguaje y el lenguaje destila el sentido que le damos a nuestro mundo de forma colectiva. No flota a la deriva. Más bien está condicionado por las maneras que tenemos de lidiar con la realidad, con los valores de una sociedad, sus tradiciones, suposiciones, instituciones y circunstancias materiales (2017, 163-164).

En atención a lo anteriormente expuesto, un texto narrativo debería despertar en el lector la apertura a lo que Ricoeur llama metáforas vivas, es decir, aquellas que nos revelan otra mirada sobre lo que habitualmente vivimos como la realidad. De nuevo, en palabras de Eagleton:

Los lectores nos enfrentamos a un texto literario con toda clase de creencias y suposiciones, a menudo de tipo inconsciente [...] A menos que un lector formule suposiciones continuamente, un texto literario no funciona [...]. Un modo de intentar captar un poema o una novela en conjunto consiste en investigar sus temas, es decir, las varias preocupaciones que encontramos en la obra (2017, 165-168).

Por otra parte, se puede apreciar que el lugar que le da Michel Foucault a la literatura, es también pertinente para el enfoque que se propone en esta investigación, al promover una metodología de la lectura que posibilite la apertura de metáforas vivas, pues, siguiendo al autor: 
el propio arte, trátese de la literatura, la pintura o la música, debe establecer una relación con lo real que ya no es del orden de la ornamentación, del orden de la imitación, sino del orden de la puesta al desnudo, el desenmascaramiento, la depuración, la excavación, la reducción violenta a lo elemental de la existencia (2010, 200-201).

\section{MÉTODO}

El camino que se siguió en la investigación, es el de la hermenéutica literaria, ya que en ella encontramos la viabilidad pedagógica de propiciar una refiguración del mundo de la vida, por parte del lector. La recuperación de la narrativa -perdida en la educación que sirve a fines donde predominan la instrucción y la adaptación al campo laboral, en detrimento de finalidades educativas para la vida cotidiana, las cuales demandan la atención a la diversidad-encuentra una fuente de sustento teórico y metodológico para la investigación y la práctica educativa, en la hermenéutica de Paul Ricoeur (1999). Su concepción hermenéutica está dirigida a los textos en un sentido amplio, que se refiere a toda obra inscrita; por ello, podemos considerar tanto los textos en la oralidad, en la escritura como en los medios electrónicos. Concretamente, se aplica aquí su conceptualización de la identidad narrativa, como construcción colectiva e individual. Consideramos pertinente esta metodología, porque trata acerca de la forma en que entramos al mundo en la infancia, como señala Gadamer (2000), en la sabiduría del campo práctico en el que se aprende mediante narraciones. En la cultura de la escritura -propia de la educación escolar-, los géneros que han servido para contar historias, desarrollan para Ricoeur: “... una especie de inteligencia que puede llamarse inteligencia narrativa, y que está mucho más cerca de la sabiduría práctica y del juicio moral, que de la ciencia y más generalmente del uso teórico de la razón (2009, 195). Pues, si bien los géneros narrativos trabajan en una dinámica de sedimentación y de innovación, podemos observar que los géneros narrativos tradicionales más empleados en la relación cara a cara, o la lectura de textos escritos, han ido perdiendo su lugar, el cual está siendo ocupado cada vez más, por los medios electrónicos, lo cual en sí no es negativo, pero exige un estudio acerca del origen de las narraciones con las que se forma actualmente el sujeto, a través de ellas. Aquí cabría preguntarnos ¿quién cuenta ahora las historias que forman en la infancia?, ¿qué efectos tiene la recepción de estas historias en el actuar cotidiano?, ¿cómo afectan la formación? El paso de la narración oral a la escrita trajo como consecuencia la lectura en voz alta hecha a otros que escuchan, pero también la lectura individual, en silencio. En el primer 
caso, el comentario vuelve a la experiencia comunitaria de la oralidad, mientras que en el segundo, se fomenta el aislamiento, un proceder muy característico del desarrollo académico. Por este motivo, enfatizamos que el cultivo de la hermenéutica literaria -mediante el comentario y la recepción que este genera- devuelven la relación formativa a la comunidad entre los lectores, reunidos en las aulas universitarias, en el caso que se estudia en esta investigación.

Las narraciones relacionan las historias que cuentan, con la vida de sus receptores. Esta es la manera en que la hermenéutica de Ricoeur rompe la dicotomía que afirma que la vida es vivida y los relatos son contados, pues la narración escrita -desde el punto de vista hermenéutico- es mediadora entre el texto y la realidad como su referente (referencialidad), también media entre los sujetos (comunicabilidad), y es mediadora entre el individuo que lo produjo (comprensión de sî). La hermenéutica busca en el texto narrativo “... descubrir los nuevos rasgos de referencialidad no descriptiva, de comunicabilidad no utilitaria, de reflexibilidad no narcisista, engendrados por la obra literaria” $(2009,199)$.

Ricoeur se interesa por las narraciones que, al fijar la experiencia de las acciones humanas en circunstancias históricas particulares, se vuelven un rico acervo para la autorreflexión. De esta manera, tanto los relatos de la Historia dentro de las disciplinas de las ciencias sociales, como los relatos de la Literatura, que son creación estética, se constituyen en documentos que configuran la experiencia humana, y su interpretación puede tener provecho en una actividad que posibilite la refiguración individual y colectiva de los valores que orientan la acción en una cultura, lo cual le proporciona un carácter ético a la lectura. En el tema que trata esta investigación, la orientación a la que se alude es hacia la diversidad. Es importante señalar que la dirección hacia la Historia y hacia la Literatura, revela que Ricoeur ve en estas actividades la manera en que se relaciona la escritura con la oralidad, en la narración de los acontecimientos concordantes y discordantes del actuar humano, en su búsqueda de significación en el mundo. En consecuencia, en este modelo investigativo, un modo de conocimiento pertinente mediante el que se conseguirían las finalidades descritas, es el de la argumentación narrativa, pues se entiende que el sujeto se comprende narrándose. Este tipo de argumentación narrativa es una forma de conocimiento mostrativo, no prescriptivo. La construcción del objeto de estudio sería el texto (tejido de significaciones), en el que las pre-comprensiones de la realidad o mundo de la vida, tendrían que configurarse en un instrumento que pusiera en claro las concepciones problemáticas de las manifestaciones de la diversidad.

Hernández doi: https://doi.org/10.36799/el.v4i1.57 Volumen 4, Número 1, Año 2019, ISSN: 2448-5942 
Siguiendo la perspectiva ricoeuriana, el texto le permite al lector salir de sí mismo para comprender a otro, y en ese proceso volver a sí mismo con la experiencia de la interpretación, que le hace ver un problema compartido con el otro del relato. Ello contribuye a la evaluación moral de los personajes y a la imputación, es decir, a la concepción de un sujeto responsable de sus actos. Para Ricoeur, la intelección narrativa se asemeja al juicio moral, porque explora los caminos que conducen o no a la felicidad y a la desgracia. Se da a través de variaciones imaginativas, las cuales permiten al lector salir del imaginario propio. De esta manera, la narración proyecta el análisis del sí mismo en otra dirección, pues el relato permite conocernos más ampliamente que los límites de su marco. Esto significa que los lectores podemos salir del mundo del texto, para continuar en la vida cotidiana la reflexión en la que participamos.

Este paso conduce a Ricoeur a cuestionarse cómo se convierte el yo en refigurado. Su respuesta es que ello es posible, mediante el recurso de ponerse en el lugar del otro construido en la narración; lo cual corresponde a una actitud en la lectura, en la que el lector pudiera imaginar "Yo soy otro". Este trabajo de interpretación puede provocar la ruptura de una ilusión, oponer lo auténtico a lo inauténtico, como resultado de una hermenéutica crítica.

El círculo hermenéutico como estrategia de indagación, trata de poner en cuestionamiento los conceptos, los recursos simbólicos, que están relacionados con las características temporales de nuestra comprensión práctica. En el caso de la investigación educativa, el cuestionamiento aplicaría a la formación de profesionales de la educación, mediante la elaboración de una explicación que sirva como modelo de comprensión de las circunstancias que alteran la concordancia y se viven como momentos discordantes. Con ello se considera que se cumpliría con fines educativos más allá de los de mera instrucción. La narración como método de investigación, sirve como mediadora entre acontecimientos individuales y una historia como un todo; integra factores heterogéneos que hacen inteligibles los acontecimientos que, en el campo práctico, nos parecen dispersos. El círculo hermenéutico concluye con una vuelta al campo práctico o mundo referencial, no en la forma de un círculo vicioso, sino de una espiral -reflexión sobre un mismo punto pero a alturas diferentes-, lo cual significa que la indagación no se considera como concluida definitivamente, sino como un acercamiento hacia la comprensión.

Con el marco hermenéutico ricoeuriano -presentado en los párrafos anteriores-, la metodología que se aplica en esta fase de la investigación para lograr el propósito lector argumentado, proviene de la hermenéutica de Giorgio Agamben, seguidor de Michel Foucault. 
La elección de esta metodología se justifica pues se considera idónea para cultivar la formación ética para la construcción de valores educativos en los profesionales de la educación, ya que parte de una reflexión que cuestiona los discursos que conforman lo que concebimos como la realidad. En efecto, esta metodología se basa en descubrir lo signado en los signos, es decir las huellas ideológicas en los discursos, las instituciones, los edificios, mostradas en el caso específico de la ceguera en el texto de estudio seleccionado. El dispositivo, es decir lo que dispone de los sujetos en la ceguera, es la red que se establece entre estos elementos. De acuerdo con Agamben (2015a), el dispositivo tiene una función estratégica concreta y se inscribe en una relación de poder. Resulta del cruce de relaciones de poder y de relaciones de saber. Los seres vivientes estamos sujetos a dispositivos. Así, el sujeto es lo que resulta de las relaciones entre los vivientes y los dispositivos. Son procesos de subjetivación múltiples, pues los dispositivos han aumentado en esta época: "Probablemente no sería errado definir la fase extrema del desarrollo capitalista que estamos viviendo como una gigantesca acumulación y proliferación de dispositivos" (Agamben, 2015a: 25).

Por ello, nos resulta aplicable en los estudios culturales -específicamente de la diversidad-, el método de interpretación que propone Agamben, que es el del análisis de las signaturas: "El signo significa porque lleva una signatura, pero ésta predetermina necesariamente su interpretación y distribuye su uso y su eficacia según reglas, prácticas y preceptos que hay que reconocer" $(2010,86)$. La arqueología, es decir la búsqueda del origen de donde provienen estas signaturas, sería una de las finalidades de su estudio. En este trabajo nos detenemos en las signaturas de los discursos, las instituciones, los edificios establecidos para las personas con ceguera.

Sin embargo, ya que la narrativa literaria es un objeto alrededor del cual se ha construido una metodología de estudio, considerando su peculiaridad discursiva dentro del ámbito estético, en la investigación se atiende también un método propiamente literario, pues consideramos que la hermenéutica se fundamenta en ambos enfoques metodológicos, el filosófico y el literario. El material de estudio en esta etapa de la investigación, es la novela El huésped (Nettel, 2013), cuya elección consideramos adecuada para los fines de la investigación, porque nos acerca al conocimiento y a la reflexión sobre el mundo vivido con la ausencia del sentido de la vista. Esta novela ofrece múltiples abordajes temáticos para la interpretación. En este caso, el artículo se concentra en el abordaje del tratamiento hacia las personas con ceguera, tema del cual esta novela 
ofrece varias vetas de estudio. Para ello específicamente se toma de Agamben la metodología de las signaturas que nos permiten, como lectores, comprender la representación de la diversidad, en este caso, ontológica -la ceguera como una forma de existencia-. La pregunta básica que se plantea al respecto es ¿De qué actitudes hacia las personas con ceguera nos permite percatarnos la narrativa de Nettel en esta novela?

Como propone Paul Ricoeur (1999), seguir al personaje en su trayectoria narrativa es una manera de identificarse con la idea que se trabaja a lo largo del recorrido narrativo. Por otra parte, la configuración de la novela es importante para comprender la intencionalidad del texto. Por ello, el análisis de la novela toma en cuenta el trayecto del personaje y la manera en que la estructura del relato influye en la resolución del conflicto. La metodología consiste en interpretar las signaturas representadas en los discursos lingüísticos, institucionales y físicos mediante edificios configurados en la novela.

\section{RESULTADOS}

$\mathrm{Al}$ analizar la configuración de la novela en estudio, podemos percatarnos de que su estructuración en tres partes, permite seguir al personaje en las correspondientes etapas de su trayectoria en la ceguera, que inicia con las primeras manifestaciones en la niñez, cuando la enfermedad se manifiesta en Ana, el personaje narrador, como un desdoblamiento de su persona, que le provocaría un estado interior incompatible con la socialidad "normal" que, desde la infancia, le impidió integrarse en un grupo y entablar relaciones de amistad:

Sabia que dentro de mí también vivía una cosa sin forma imaginable que jugaba cuando yo jugaba, comía cuando yo comía, era niña mientras yo lo era. [...] Sabía que su respiración era semejante a un pulpo, cuyos tentáculos pegajosos desplegaba por la noche a lo largo de mi cuarto; sabia que nada le resultaba tan hiriente como la luzy que, si alguna vez llegaba a dominarme, me condenaría a la oscuridad más absoluta; sabia en pocas palabras que era mi peor enemiga (Nettel, 2013, 13-14).

....Esta etapa del trayecto de Ana, en la que lidiaba con ese doble que llamaba La Cosa, está caracterizada por el ensimismamiento y la soledad, como consecuencia de la dificultad para comprender lo que estaba sucediendo en su cuerpo y, en forma paralela, lo que acontecía en su entorno familiar con la muerte de su hermano y la separación de su madre y su padre.

Hernández doi: https://doi.org/10.36799/el.v4i1.57 Volumen 4, Número 1, Año 2019, ISSN: 2448-5942 
Esta primera parte concluye cuando Ana se da cuenta de que su enfermedad la incluirá en un ámbito particular de vida, que implica la pertenencia a un grupo de personas. Eso la conduce a salir de su ensimismamiento para relacionarse con el mundo en el que siente que será incluida: "Sí, los ciegos existían, qué le íbamos a hacer. Poco a poco, me convencí de que sería más provechoso observarlos. Para luchar contra La Cosa era imprescindible conocerla. De nada iba a servirme seguir huyendo" (Nettel, 2013, 51).

El trayecto del personaje continúa con el acercamiento al mundo de la ceguera, desde los ámbitos institucionales y los contrainstitucionales, en la juventud de Ana. En el plano de su futura inserción social como invidente, Ana recurrió a la observación de las personas con ceguera:

Hacía tiempo que observaba constantemente a los ciegos. Me encontraba a menudo con ellos en la calle, en los cafés, en el supermercado. Cuando esto sucedía, paraba cualquier actividad que estuviera realizando para estudiar su comportamiento. Pero una investigación debe basarse en datos y no sólo en especulaciones, no bastaba con verlos caminar o analizar sus trucos para desenvolverse en lugares públicos, tenía además que averiguar cuáles son los problemas cotidianos, descifrar la mentalidad del invidente. Me intrigaban los alcances de su olfato, de su intuición (Nettel, 2013, 56-57).

Esta actitud de observación, que Ana siguió como camino para involucrase en la forma de existencia de las personas con ceguera, revela su capacidad de advertir que se desarrollan otras capacidades, tales como las que ella menciona como trucos para desenvolverse, los problemas específicos por resolver de un invidente, el tipo de mentalidad que desarrollaban, las potencias de ellos en el uso de los otros sentidos, la peculiaridad de sus intuiciones. Durante esa observación se encuentra con la posibilidad de conocer el mundo institucional destinado a las personas con ceguera:

Una tarde, mientras paseaba por el barrio, vi que uno de ellos repartía volantes impresos. Me aproximé para observarlo de cerca y acepté uno de los papeles que me ofrecía. Era el anuncio de un instituto de atención para ciegos situado a pocas cuadras de abi, en la colonia Roma. Deposité una moneda en la cajita de metal que colgaba de su cuello y regresé a casa agitando el volante. Decidi visitar el instituto esa misma tarde (Nettel, 2013, 57).

En esta parte del relato, llama la atención la circunstancia de que la persona que invitaba con los volantes a conocer la institución, lo hacía para recabar recursos monetarios para la Hernández. doi: https://doi.org/10.36799/el.v4i1.57 Volumen 4, Número 1, Año 2019, ISSN: 2448-5942 
institución, en un gesto de solicitud de limosna. Mientras que Ana se interesaba por la forma de vida alternativa que encontraba en los invidentes, aquí tenemos el principio de una advertencia de otra manera de observar a estas personas, que desde el punto de vista del análisis que se pretende en este trabajo, indicaría una signatura institucional, es decir que se revelan las características asistenciales o de beneficencia del instituto referido.

El interés despertado en Ana hacia los ciegos, la impulsa a visitar el instituto de atención para ciegos, que anunciaba el volante. El instituto se ubicaba en un edificio de la Colonia Roma que, de acuerdo con la percepción de Ana era “... bellísimo por fuera y por dentro rayano en la sordidez" (Nettel 2013, 73). La sordidez referida va siendo más profundamente percibida por Ana a medida que va introduciéndose en la vida de la institución:

En el pasillo se escucharon unos pasos que poco a poco se convirtieron en la figura blanca y regordeta de una enfermera. Conforme se fue acercando, noté que su traje estaba percudido. Este personaje desaliñado tampoco me sorprendió; revelaba -y fue como si desde entonces yo lo bubiera intuido - la verdadera personalidad del instituto (Nettel, 2013, 58).

Esta personalidad fue poco a poco descubierta por Ana, mediante los discursos signados, como por ejemplo, la manera de nombrar a sus habitantes: "Un manicomio no debe ser muy diferente, pensé. Además, esa manera de llamar a los ciegos “internos” me preocupaba” (Nettel, 2013, 62). La misma percepción tuvo cuando se encontró con la cocinera y su mandil manchado de comida, al igual que la enfermera con su uniforme percudido, lo cual representa signaturas que revelan la idea de que los habitantes del instituto no requieren ser atendidos por personas con adecuada presentación de limpieza. Algo así como "ojos que no ven, corazón que no siente”. Esta actitud se revela también en la prohibición de disfrutar del sol en los jardines, reservados sólo para los profesores; o la ausencia de espacios de privacidad, como si los otros sentidos no estuvieran activos. En este aspecto, finalmente se representa la signatura institucional de acuerdo con la cual las personas con carencias visuales son inadecuadas para desempeñar funciones dentro de la organización ciudadana:

No tardé mucho en comprender que esa institución, supuestamente creada para ellos, los tomaba raramente en cuenta. ¿Cuántas personas en el equipo de maestros, psicólogos, camareros y enfermeras eran ciegos o lo habian sido? ¿Cuántos participaban en las decisiones administrativas? Que yo supiera ninguno (Nettel, 2013, 75).

Hernández doi: https://doi.org/10.36799/el.v4i1.57 Volumen 4, Número 1, Año 2019, ISSN: 2448-5942 
Un personaje clave que interviene en esta etapa del trayecto narrativo de Ana, es el Cacho, uno de los profesores del instituto, llamado así porque tenía una pierna amputada: "No fue hasta terminar el mes cuando conocí a aquel que sería mi Virgilio pero también mi dolor de cabeza en el instituto" (Nettel, 2013, 70). Esta referencia intertextual da a conocer la percepción de Ana de su trayecto como un viaje por el infierno. En el trayecto de Ana, guiada por el Cacho, acontece una salida de ese control ejercido por los discursos, las instituciones, los edificios que encierran la diversidad. Esta salida es la rebeldía concretada en un mundo también marginal, pero que se ofrece como un ámbito de libertad de existencia para los "diversos". Así, la inmersión en la clandestinidad, ejercida en el mundo de la ciudad nocturna y en el mundo subterráneo del metro de la Ciudad de México, se presentan como la salida liberadora o de resistencia de los discursos, las instituciones y los edificios que conforman el dispositivo de la diversidad por la ceguera. Esta actitud de resistencia, Ana la percibe cuando encuentra en los andenes del metro a Lorenzo, un joven que escapó del instituto -debido a la influencia de las ideas del Cacho-, y le pregunta por qué huyó, a lo que él responde:

Aunque no lo crea, me tomó muchos meses decidirlo, pero no podía permanecer más tiempo encerrado. No tengo nada contra el instituto, sé que ha ayudado a mucha gente, pero creo que es una etapa de transición que se prolonga demasiado. El encierro atrofia. ¿Se da cuenta?, algunos ni siquiera conocen todos los pasillos del edificio. Están acostumbrados a un solo recorrido y temen modificarlo. Los músculos se entumen abi dentro. ¿Ha notado cómo caminan los que viven ahi? Pero el peor embotamiento no es ése, sino el mental, la falta de retos y horizontes. Nos obligan a adoptar un comportamiento uniformado, que nos hace ver apacibles, ¿̇ero qué sucede con nuestra verdadera personalidad? Se queda abí, contenida, esperando el momento de salir a la luг, aunque sea en un ataque de nervios (Nettel, 2013, 177).

En la culminación de su trayecto hacia la ceguera, Ana experimenta un cambio contrastante en su cuerpo, pues por una parte lo percibe torpe, pero por otra, experimenta un impulso erótico, que manifiesta una expresión de potenciación de los otros sentidos:

En el espejo, mi cara se veía casi esquelética: dos pómulos salientes, irreconocibles, ocupaban el lugar de los cachetes que nunca volvería a tener. No era mi rostro ya, sino el del huésped. Mis manos crispadas, la forma de caminar, reflejaban ahora una torpeza pastosa, la lentitud de quien ha dormido muchas horas e intenta despabilarse de golpe. Al mismo tiempo, descubría con asombro una sensualidad nueva. Mis caderas y mis pechos, antes realmente pueriles, eran cada vez más prominentes, como si los dominara una voluntad ajena. Poco a poco, el territorio pasaba bajo su control (Nettel, 2013, 124).

Hernández doi: https://doi.org/10.36799/el.v4i1.57 Volumen 4, Número 1, Año 2019, ISSN: 2448-5942 
La última parte acontece cuando Ana sufre la pérdida completa de la visión, y enfrenta la toma de decisión entre los dos ámbitos de vida en la ceguera, que se le presentan como alternativas. En este trayecto, la elección se va también manifestando como una respuesta del personaje hacia los dispositivos que encuentra como ejercicio de un poder, que coloca a las personas con ceguera en una circunstancia de pasividad y marginación, en los ámbitos familiar y social. Estos dispositivos ubican a las personas con ceguera en lo que Agamben (2004) llama estado de excepción, que significa vidas de las cuales se dispone, disminuyendo o anulando su desarrollo personal pleno y su participación ciudadana. El Cacho estimula a los ciegos a rebelarse contra su estatus institucional dado por otros. El Cacho los incita a salir de la pasividad:

Aqui se habla de que los internos deben aprender a valerse por sí mismos y ocurre todo lo contrario. Miralos, no se atreven a hacer nada sin pedir permiso. Terminan convertidos en mascotas de departamento a las que se saca a pasear dos veces al día alrededor de la cuadra (Nettel, 2013, 112).

El Cacho es el líder de las personas que habitan el mundo de la marginación, que es el de la noche, a las cuales incita a la profanación de las instituciones "diurnas", como las de la pretendida democracia.

\section{DISCUSIÓN}

Con la fundamentación que nos aportan los autores citados en este artículo, el paso siguiente es pensar sobre la tarea pedagógica que se deriva del análisis de la novela El huésped. El marco de inicio consiste en propiciar en el aula con profesionales de la educación -en formación o en ejercicio profesional-, el momento que Ricoeur llama refigurativo, es decir la apertura a una nueva mirada sobre la diversidad -en este caso por la ceguera-, en lo que Ricoeur llamaría una metáfora viva, que abra nuevos criterios para formar valores frente a la diversidad. Si lo planteamos en términos de Agamben, esta metáfora viva permitiría una perspectiva ética, al considerar las signaturas como metáforas muertas que nos guían en la vida cotidiana. Para nutrir este marco que alude a las finalidades de la educación, ha sido enriquecedora la discusión de Hans Ulrich Gumbrecht sobre la necesidad actual de las humanidades. El autor afirma que hoy en día se requiere reenergizar las Humanidades, no ya como proyectos pedagógicos “ . ... ansiosos por "educar" generaciones enteras, sociedades y naciones" (2007, 94). Lo que el filólogo propone, en vez de esto, es volver al concepto de vivencia (Erlebnis). En palabras del autor: 
Una de las razones por las que esta vuelta me parece tan plausible es la imposibilidad de compatibilizar la noción de Erlebnis con la esfera de lo colectivo y lo social. Podemos comunicary "compartir experiencia" como aquello que está y interpretado y moldeado en conceptos - pero la vivencia, como aquello que precede a tal interpretación, debe quedar como algo individual (2007, 95).

Lo que podemos derivar de la propuesta de Gumbrecht, en relación con la formación de profesionales de la educación, es que la construcción del conocimiento se daría en la vía de las ciencias sociales como comunicación de conceptos ya interpretados, y también por la vía de la experiencia estética - en nuestro caso a través de la narrativa literaria- mediante la vivencia. Siguiendo a Gumbrecht, la vivencia explicaría las razones por las que la investigación y la enseñanza pueden llegar a tener efectos formativos en los estudiantes. En este aspecto, el autor revitaliza el concepto filosófico de formación (Bildung) de la hermenéutica de Hans-Georg Gadamer, que hemos incorporado como categoría educativa en la investigación desde sus inicios. Para Gumbrecht, la manera en que esto puede suceder es por medio de un trabajo pedagógico que consista en “... identificar y preparar objetos de estudio de tal complejidad y luego, al menos parcialmente, escenificar los encuentros de nuestros estudiantes con ellos” (2007, 96).

Esta vivencia mediante la narrativa literaria, introduciría al lector en la complejidad de la condición humana que, como dice Agamben, podría conducir a las preocupaciones que conforman dicha condición:

Como el iniciado, asistiendo en la penumbra eleusina a la evocación mímica o danzada del rapto de Kore en el Hades y de su reaparición anual en la tierra en primavera, penetraba en el misterio y encontraba abi una esperanza de salvación para su vida, asi el lector, siguiendo la intriga de las situaciones y eventos que la novela teje piadosamente o con ferocidad en torno a su personaje, participa de alguna forma a su modo e introduce su propia existencia en la esfera del misterio $(2016,13)$.

En el caso de El buésped, el lector experimentaría la ferocidad de las situaciones y eventos de la narrativa, ya que la perspectiva de la diversidad que presenta Nettel en esta novela, es oscura ${ }^{4}$, es decir, se plantea una visión descarnada de una realidad de la diversidad. Tanto las signaturas provenientes de la persona ciega como de los otros hacia ella, deberían hacernos reflexionar sobre nuestro involucramiento en este discurso o en la aceptación del mismo, que

\footnotetext{
${ }^{4}$ Aspecto de la obra de Nettel sobre el que han llamado la atención autores como Oswaldo Estrada (2014, 253-
} 281) y Jorge Volpi (2010, 200-204). Hernández. doi: https://doi.org/10.36799/el.v4i1.57 Volumen 4, Número 1, Año 2019, ISSN: 2448-5942 
expresamos como verdad. La condición ontológica de la persona con ceguera, tal como la presenta la autora, puede conducir al lector a una comprensión específica del tema que, desde el punto de vista de la educación en la diversidad, se pretendería que diera qué pensar, que moviera las ideas preconcebidas o sedimentadas respecto del discurso sobre la diversidad, en este caso, la diversidad por la ceguera, como lo plantea Agamben en relación con la creatividad del lenguaje: ¿Qué es la poesia, sino una operación en el lenguaje que desactiva y vuelve inoperosas las funciones comunicativas e informativas para abrirlas a un nuevo, posible uso? O, en los términos de Spinoza, el punto en que la lengua, que ha desactivado sus funciones utilitarias, descansa en si misma, contempla su potencia de decir $(2016,49)$.

Con la intención de explorar la puesta en práctica del análisis de la novela El buésped, se llevó a cabo un ejercicio en un grupo de 10 estudiantes de posgrado -integrado por docentes frente a grupo en diversos niveles educativos-. El seminario en el que se llevó a cabo la práctica, fue sobre hermenéutica en investigación educativa. Los participantes del seminario habían estudiado antes de esta experiencia, a autores como Giorgio Agamben, Michel Foucault, Jean Luc Nancy, Paul Ricoeur, Hans Georg Gadamer. Por tal motivo, tenían un bagaje hermenéutico que podrían aplicar en la comprensión de la novela. Tal como hemos afirmado anteriormente (Hernández 2018), la lectura de textos literarios no ha sido una práctica integrada al desarrollo curricular en la formación de profesionales de la educación y si se ha realizado, ha sido de manera poco frecuente y más bien con una intencionalidad de ilustrar algunos conceptos manejados dentro de las ciencias sociales. En el caso que exponemos en este artículo, se trató de desarrollar el estudio del tema desde el plano de la sensibilidad que demanda el carácter estético del texto literario. Es decir, se procuró introducir en el comentario, la comprensión de la argumentación narrativa.

La aplicación de esta propuesta de lectura en la práctica pedagógica dentro del salón de clases, consistió en propiciar en los estudiantes la vivencia que puede suscitar la novela. Como actividad introductoria, se puso en práctica una dinámica grupal que consistió en que, agrupados en pares, uno de los estudiantes cerrara los ojos -para experimentar la ausencia de visión- y se dejara conducir por su par en un recorrido por un trayecto sinuoso, con obstáculos existentes. Después, la conducción se dio en una simulación de circunstancia de salvamento, por ejemplo en caso de sismo - circunstancia muy probable de ocurrir en la Ciudad de México-. Los participantes que sí veían, guiaron a sus personas ciegas hasta un punto de seguridad. En los 
comentarios que siguieron a esta actividad, se exploró la diferencia entre considerar a la otra persona como carne o como cuerpo. Esta diferenciación permitió percibir que, al considerar al otro como cuerpo, desarrollamos una actitud más amplia en el sentido hermenéutico -en la comprensión de sus circunstancias-, que si sólo lo consideramos como carne.

Una vez finalizada la anterior dinámica introductoria, se procedió al comentario de la novela El huésped, cuya lectura se había efectuado en tiempo extra-clase. Como inicio se invitó a los participantes a expresar un comentario sobre su experiencia con la lectura de la novela. Posteriormente se continuó con la participación de quien conducía la actividad, mediante la preparación previa de la guía de conducción. En esta tarea la función del docente consistió, en primer lugar, en realizar una interpretación propia de la novela -tal como se presentó en el apartado de resultados de este artículo-, con el fin de estar en posibilidad de guiar en el método y la metodología de interpretación, además de preparar el guion para propiciar la vivencia. Al respecto, hay que agregar que un objetivo concomitante en la tarea vivencial con los estudiantes, es el de formar lectores autónomos, es decir, que logren el hábito de acercarse a la lectura de textos literarios por propia iniciativa, y que busquen la comunidad para el comentario interpretativo, entre sus pares de profesionales de la educación y entre sus estudiantes.

El procedimiento interpretativo inherente al quehacer hermenéutico es el recurso de la pregunta, que surge del extrañamiento que provoca la narrativa. Este recurso ubica la propuesta en el nivel de la didáctica, como concreción de la propuesta educativa. En el momento formativo de los lectores, las preguntas pueden ser sugeridas por el propio docente, pero preferentemente se tendería a propiciar que sean generadas por los estudiantes, de acuerdo con la lectura metódica y la vivencia. Algunos ejemplos de las preguntas preparadas para el comentario, son los siguientes:

* En relación entre el cruce de relaciones de poder y de relaciones de saber que generan los dispositivos, una pregunta que surge es ¿por qué entre los cinco sentidos, el de la vista es uno de los que está más sujeto a dispositivos cuando se sufre su pérdida?

* Cuando se habla de diversidad, cabría preguntarse ¿divergente de qué discurso?

* ¿Cuáles son las signaturas que definen en Ana la ubicación de sí misma ante la actitud social frente a esta manifestación de diversidad?

* ¿De qué manera podemos ponernos en el lugar de este personaje, al conocer su proceso interno de devenir una persona ciega?

Hernández doi: https://doi.org/10.36799/el.v4i1.57 Volumen 4, Número 1, Año 2019, ISSN: 2448-5942 
* ¿Cómo contribuye la configuración narrativa de esta novela, para propiciar en los lectores una actitud ética en la comprensión de ese otro, que consideramos diverso por tener problemas con el uso de uno de sus sentidos?

Este momento de la lectura abordó la relación entre el mundo de la ficción y la realidad empírica de los participantes. Esta experiencia aplicativa de la propuesta fue realizada de manera parcial y exploratoria en función de la propuesta completa que se presenta en este artículo, pues se introdujo en un programa de seminario que tenía por objetivo estudiar la aplicación de la hermenéutica en la investigación educativa. El trabajo con la lectura de El huésped se realizó como una actividad en ese contexto.

En relación con la experiencia en la aplicación de la propuesta, se puede decir que fue recibida con entusiasmo. El propósito de construir valores hacia la diversidad, mediante criterios provenientes de un tipo de discurso como el de la narrativa literaria, tuvo un logro significativo en la construcción colectiva efectuada por el grupo. No obstante, hay que señalar las dificultades acontecidas en la lectura, debidas al tipo de abordaje que demandan los textos literarios. La confrontación con el acercamiento lector entre los textos de las ciencias sociales y los de la narrativa de ficción, fue evidente entre los participantes -salvo el caso de una profesora de literatura-. Esta confrontación se manifestó, por ejemplo, en el aspecto de la resistencia al proceso de imaginar, que se contrapone con el apego a un anclaje en lo que llamamos la realidad. Sin embargo, considero que este hecho hace más clara la necesidad de elaborar propuestas educativas como la presente, sobre todo tomando en cuenta que esta formación es de profesionales de la educación.

Otra actividad pedagógico-didáctica se podría hacer, tendría lugar en el plano del análisis del discurso. Por ejemplo, al principio de este trabajo, se hacía referencia a que la existencia de Ana en la pérdida de la vista, generaba una circunstancia que le impedía integrarse en una socialidad normal, que le permitiera ingresar en la comunidad de la infancia, como vía de establecimiento de relaciones de amistad una vez que, por medio de la escuela, se amplía el círculo de los lazos entre las personas, lo cual sería el inicio de la socialidad que se continuaría realizando en el transcurso de la vida. Al respecto, habría que analizar en el tratamiento pedagógico con la lectura de esta novela, una práctica lingüística que ejercemos al marcar entre comillas una determinada palabra, como es el caso en este trabajo con la palabra normalidad, pero también con los términos diurnas, diversos, con la expresión de sabiduría proveniente de 
la cultura de la oralidad -que dice que ojos que no ven, corazón que no siente-, las cuales en algunas partes de este artículo, se han usado marcadas entre comillas. La relevancia de este ejercicio deriva de que, aunque nos refiramos frecuentemente a ciertos términos especificando que los ponemos entre comillas, pocas veces nos detenemos en el examen de que este acto de lenguaje significa la elaboración de una reflexión discursiva. El inicio de este examen lo podemos plantear con el análisis que encontramos en la hermenéutica de Agamben:

¿Qué significa, de hecho, poner una palabra entre comillas? Con ellas quien escribe toma distancia del lenguaje: indican que un determinado término no es tomado en la acepción que le correspondería, que su sentido ha sido alejado (citado, llamado hacia afuera) del habitual, aunque no del todo amputado de su tradición semántica. Ya no se quiere o no se puede usar simplemente el antiguo término, pero tampoco se puede o se quiere encontrarle uno nuevo. El término entrecomillado es mantenido en suspenso en su historia, es pesado, por lo tanto, al menos de manera embrionaria, pensado (2015b, 111).

A partir de la cita anterior, se puede plantear la manera en que el lenguaje nos permite cuestionar los significados con los cuales organizamos la vida cotidiana. En este aspecto, entrecomillar la expresión y las palabras mencionadas, como se hizo en la perspectiva interpretativa de la novela El huésped, conduce a realizar una puesta en cuestión sobre las valoraciones que se realizan sobre la diversidad. Para continuar con la reflexión que aporta Agamben sobre este manejo del lenguaje, que posibilita la crítica sobre las metáforas muertas e invita a la creación de metáforas vivas, en seguida podemos analizar lo que al respecto dice el autor:

Quien ba colocado una palabra entre comillas ya no puede liberarse de ella: suspendida en el aire en su impulso significante se vuelve insustituible para él o, más aún, ahora, no puede prescindir de ella. De ese modo la propagación de las comillas delata el malestar de nuestro tiempo respecto del lenguaje: representan las murallas -delgadas pero infranqueables-de nuestro cautiverio en la palabra. En el círculo que las comillas estrechan alrededor del vocablo ha quedado encerrado también el hablante (2015b, 112).

En la transferencia didáctica de la reflexión que se ha puesto como objetivo del trabajo de lectura de la novela de Nettel, otra actividad complementaria sugerida fue el análisis del documental Potentiae, del director Javier Toscano (2016). En este texto fílmico, el realizador muestra una visión de la vida cotidiana de personas que, como lo plantea el documental, se familiarizan con un modo de existencia con la ausencia de una parte de su cuerpo como la vista, 
alguna(s) extremidad(es); o de personas que tienen impedimento para el control de sus movimientos, o que existen con el síndrome de Down, entre otras circunstancias. Esta actividad evidenciaría también, un interés actual en el tratamiento del tema desde una perspectiva comprensiva hacia la diversidad y a la vez crítica de los discursos sobre la misma. Debido a que la proyección de este documental permaneció por muy escaso tiempo en la sala de cine en donde se exhibía, el grupo de participantes no pudo realizar esta actividad.

En conclusión, planteamos que una relación entre la literatura y la educación se puede realizar mediante la lectura hermenéutica. Este enfoque de lectura persigue despertar la idea y el sentimiento de que el problema humano que nos plantea la novela nos atañe, no sólo porque podríamos ser afectados por ello, sino también por la relación con el otro que ubicamos en la diversidad. Este enfoque responde a lo que Michel Foucault considera ocuparnos de la manera de vivir, cuidar de sí, lo que significa “... puesta a prueba, puesta en cuestión, examen, verificación de la vida" (2010, 142). En este sentido, es pertinente lo que propone Agamben (2017) cuando dice que la felicidad es tener la capacidad y usarla, es decir tener la perspectiva ontológica y la ética. Si examinamos el caso de la ceguera, podemos considerarla como una capacidad distinta que, sin embargo, se desprecia en función de privilegiar la capacidad y el uso del sentido de la vista. Desde la perspectiva filosófica que trabaja Agamben, la confinación y la marginación que se ejercen contra quien carece del sentido de la vista, son movimientos hacia estos seres humanos que tienen como efecto el impedimento para desarrollar una virtud, a partir de las potencias diversas que poseen. Si el uso de los sentidos no está predeterminado, sino que el ser humano se familiariza con ese uso cuando lo ejerce, habría que advertir que, en el caso de la visión, el sujeto con ceguera se familiariza con su nuevo ser sin la vista. Pero están los otros sentidos de los que puede hacer uso y familiarizarse con ellos. Esto explica el caso del personaje el Cacho quien subvierte el orden, gozando de su ser sin una pierna como lo explica este personaje en la cita que aparece como epígrafe en este trabajo. El Cacho profana el significado de la palabra que lo nombra y, por ello, se erige en líder de un movimiento de subversión en el que incluye a los sujetos sometidos a los dispositivos de control de las personas con ceguera. En términos de Agamben (2017), podemos decir que la persona que pierde el sentido de la vista, se familiariza con su situación ontológica, cosa que no es aceptada por un orden social instituido que privilegia el sentido de la vista, considerada como parte de la sustancia humana, a lo cual Agamben responde desde su posición filosófica, que no hay predeterminación humana, sustancialidad: “Es 
preciso que el sí mismo se constituya primero en el uso fuera de toda sustancialidad para que algo así como un sujeto - una hipóstasis- pueda decir: yo soy, yo puedo, yo no puedo, yo debo..." (2017, 119). El cuerpo se usa en la etapa de familiaridad que le corresponde, no como algo que pertenece permanentemente como la vista, sino como algo que va cambiando y que exige nueva familiaridad y uso. La persona con ceguera está en posibilidad de desarrollar otras capacidades con las cuales se familiarizaría para estar en el mundo. Lo que se cuestiona en esta novela, es el impedimento que políticamente se establece para el desarrollo de otras formas de vida. Concluyamos con las palabras de Madero, otro personaje de El huésped:

Madero me dijo ese día que las maneras de ver el mundo son miles y los ojos sólo una de ellas, un umbral intermitente que abre el paso hacia el universo de las siluetas y los colores. Los sueños, incluso los de un invidente, son otra forma de ver, la música otra. Pero junto a todas estas maneras de mirar, hay tantas o más maneras de ser ciego. "En realidad no vemos al mundo tal y como es sino como somos nosotros." Entonces habló de la ceguera de la mente, la del afecto, la del humor. Según él, se podía ser invidente sin darse cuenta (Nettel, 2013, 130).

Esta cita abre una vía para continuar la interpretación de la novela El huésped, en una línea de análisis de la ceguera como metáfora de la pasividad, en la aceptación de una ideología que impide la renovación del discurso y, en consecuencia, la acción que este suscita en la vida cotidiana en las relaciones interpersonales.

\section{REFERENCIAS}

Agamben, Giorgio. Estado de excepción. Buenos Aires: Adriana Hidalgo, 2004.

Agamben, Giorgio. Signatura rerum. Sobre el método. Barcelona: Anagrama, 2010.

Agamben, Giorgio. ¿Qué es un dispositivo? Seguido de El amigo y de La iglesia y el reino. Barcelona: Anagrama, 2015a.

Agamben, Giorgio. Idea de la prosa. Buenos Aires: Adriana Hidalgo, 2015b.

Agamben, Giorgio. El fuego y el relato. Madrid: Sexto piso, 2016.

Agamben, Giorgio. El uso de los cuerpos. Buenos Aires: Adriana Hidalgo, 2017.

Eagleton, Terry. Cómo leer literatura. México: Paidós, 2017.

Hernández doi: https://doi.org/10.36799/el.v4i1.57 Volumen 4, Número 1, Año 2019, ISSN: 2448-5942 
Estrada, Oswaldo. Ser mujer y estar presente. Disidencias de género en la literatura mexicana contemporánea. México: UNAM, 2014.

Foucault, Michel. El coraje de la verdad. El gobierno de síy de los otros. Buenos Aires: FCE, 2010.

Gadamer, Hans-Georg. La educación es educarse: Paidós, 2000.

Gumbrecht, Hans Ulrich. Los poderes de la filología. Dinámicas de una práctica académica del texto. México: Universidad Iberoamericana, 2007.

Hernández Alvídrez, Elizabeth. La hermenéutica literaria en la formación de profesionales de la educación. México: Universidad Pedagógica nacional, 2018.

Moreno-Durán, R. H. De la barbarie a la imaginación. La experiencia leída. México: FCE, 2002.

Nettel, Guadalupe. El huésped. Barcelona: Anagrama, 2013.

Potentiae. Dir. Javier Toscano. Guión Javier Toscano. Documental, 2016.

Ricoeur, Paul. Historia y narratividad. Barcelona: Paidós, 1999.

Ricoeur, Paul. Escritos y conferencias: Alrededor del psicoanálisis. México: Siglo XXI, 2009.

Volpi, Jorge. El insomnio de Bolivar. Cuatro consideraciones intempestivas sobre América Latina en el siglo XXI. México: Debolsillo, 2010. 